\title{
Comentários sobre o artigo "Avaliação radiológica do posicionamento do túnel femoral na reconstrução do ligamento cruzado anterior"
}

\section{Comments on the Article 'Radiological Evaluation of the Femoral Tunnel Positioning in Anterior Cruciate Ligament Reconstruction'}

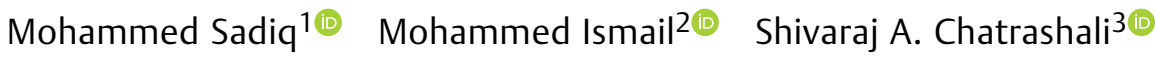 \\ ${ }^{1}$ Departamento de Ortopedia, ESIC Medical College, Kalaburagi, \\ Karnataka, Índia \\ 2 Department of Radiology, ESCI Medical College, Kalanuragi, \\ Address for correspondence Mohammed Sadiq, MD, SF1, 3rd floor, \\ Empire Residency, Gubbi Colony, Kalaburagi 585105, Karnataka, India \\ (e-mail: mdsadiqaiims@gmail.com).
} Karnataka, India

${ }^{3}$ Department of Orthoaedics, Basaveshwar Teaching and General

Hospital, Kalaburagi, Karnataka, India

Rev Bras Ortop 2021;56(1):125-126.

\section{Caro Editor,}

O debate acerca do posicionamento ideal dos túneis femorais é um tópico importante de pesquisa nos últimos tempos. Neste sentido, o artigo de Peres et al é muito relevante, já que avalia e compara os ângulos de inclinação e os comprimentos dos túneis femorais de duas técnicas comumente usadas de reconstrução do ligamento cruzado anterior (LCA). ${ }^{1}$ Achamos que estes autores fizeram uma comparação muito boa entre as técnicas transtibial e transportal, usando o ângulo de inclinação do plano coronal e o comprimento do túnel femoral como variáveis para análise das duas técnicas.

Neste estudo, os autores compararam os comprimentos do túnel femoral no plano coronal por meio da avaliação com tomografia computadorizada (TC). Este método de estimativa do comprimento femoral tem problemas graves, já que a medida é feita no plano coronal, enquanto o túnel é preparado em um ângulo de início posterior e término anterior. Isto foi explicado com exemplos de casos realizados em nosso instituto.

recebido

12 de Janeiro de 2019

aceito

19 de Fevereiro de 2019

Publicado online

Abril 1, 2019
A - Fig. 1 mostra duas imagens coronais do mesmo paciente, em que o túnel femoral foi preparado com a técnica transportal. A TC foi realizada 1 semana após a cirurgia. Os cortes coronais foram feitos em profundidades diferentes na superfície articular femoral anterior. Claramente, pode haver uma diferença significativa na medida dos comprimentos do túnel femoral em diferentes posições na superfície anterior. O motivo desta diferença é que o túnel não é criado paralelo ao eixo coronal. Ao invés disso, ele é preparado em um ângulo anteroposterior, com o ponto de entrada mais posterior do que o ponto de saída.

Recomendamos que o comprimento do túnel femoral pode ser medido com maior precisão em exames de TC no plano axial com reformatação curva, como mostrado na - Fig. 2. A reformatação curva permite a visualização de todo o túnel em seu comprimento e sua medida precisa. Um método similar de cálculo do comprimento do túnel femoral foi usado por Sim et al em seu artigo de comparação de duas técnicas para seu preparo. ${ }^{2}$

(c) 2019. Sociedade Brasileira de Ortopedia e Traumatologia. All rights reserved.

This is an open access article published by Thieme under the terms of the Creative Commons Attribution-NonDerivative-NonCommercial-License, permitting copying and reproduction so long as the original work is given appropriate credit. Contents may not be used for commercial purposes, or adapted, remixed, transformed or built upon. (https://creativecommons.org/ licenses/by-nc-nd/4.0/)

Thieme Revinter Publicações Ltda., Rua do Matoso 170, Rio de Janeiro, RJ, CEP 20270-135, Brazil 

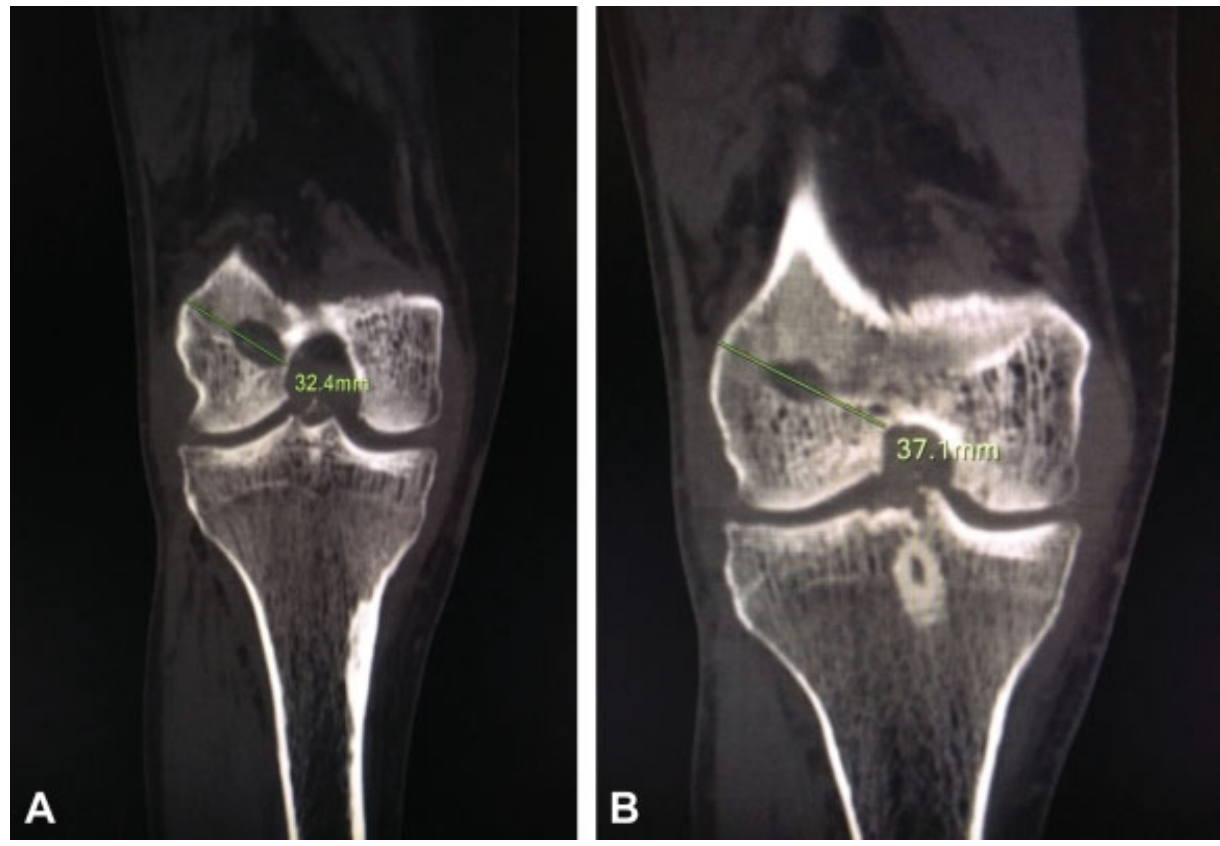

Fig. 1 Imagens coronais de tomografia computadorizada do mesmo paciente, mostrando dois diferentes comprimentos do túnel femoral em duas posições diferentes.

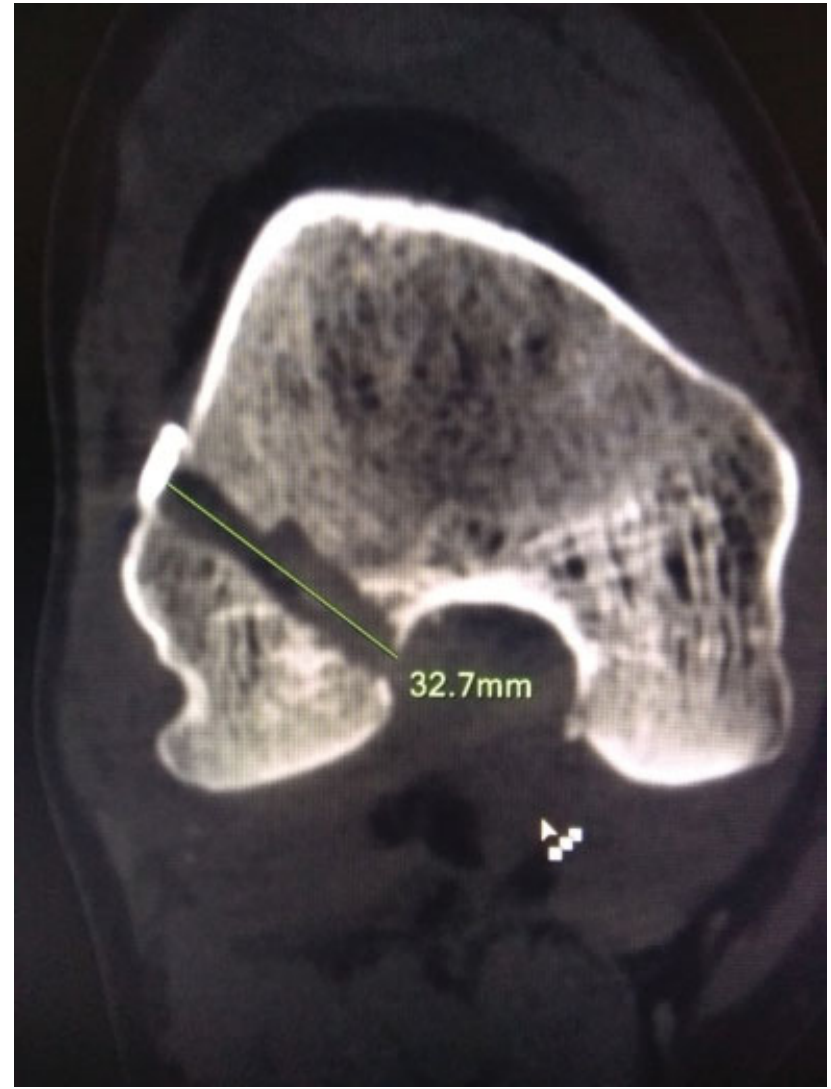

Fig. 2 Imagem axial de reformatação curva de tomografia computadorizada com visualização de todo o túnel femoral e medida de seu comprimento exato.
Excluindo esse erro, achamos que o artigo traz informações valiosas sobre a colocação do túnel femoral pelas duas técnicas.

\section{Conflitos de Interesses}

Os autores não têm conflitos de interesses a declarar.

\section{Referências}

1 Peres LR, Teixeira MS, Scalizi Júnior C, Akl Filho W. Radiological evaluation of the femoral tunnel positioning in anterior cruciate ligament reconstruction. Rev Bras Ortop 2018;53(04):397-403

2 Sim JA, Kim JM, Lee S, Song EK, Seon JK. No difference in graft healing or clinical outcome between trans-portal and outside-in techniques after anterior cruciate ligament reconstruction. Knee Surg Sports Traumatol Arthrosc 2018;26(08):2338-2344 